\title{
Implementasi pembelajaran numbered heads together dengan hasil belajar CI- C4 siswa kelas VIII
}

\author{
Andini Dwi Lestari ${ }^{1 *}$, Much Fuad Saifuddin ${ }^{2}$ \\ Pendidikan Biologi, Fakultas Keguruan dan Ilmu Pengetahuan, Universitas Ahmad Dahlan \\ Jl. Ahmad Yani (Ringroad Selatan), Tamanan, Banguntapan, Bantul. D.I. Yogyakarta 55191 \\ 1 andinidwilestari6@gmail.com*; 2fuad.saifuddin@pbio.uad.ac.id \\ *korespondensi penulis
}

\begin{abstract}
Abstrak
Penelitian ini bertujuan untuk membuktikan adanya pengaruh hubungan antara pembelajaran Numbered Heads Together terhadap hasil belajar C1C4. Metode penelitian menggunakan Quasi Eksperimen dengan desain Pretest Posttest Control Group teknik sampling yang digunakan yaitu probability sampling. Populasi penelitian ini adalah kelas VIII B dan kelas VIII D yang jumlah masing-masing kelas sebanyak 27 siswa. Pengambilan data menggunakan tes dan observasi keterlaksanaan, teknik analisis data dengan uji Mann-Whitney. Hasil penelitian menunjukkan bahwa adanya hubungan pembelajaran Numbered Heads Together terhadap hasil belajar C1 sampai C4 yang dibuktikan dengan nilai Asymp.Sig 0,000<0,05. Secara keseluruhan hasil belajar kognitif siswa sudah mencapai ranah $\mathrm{C} 4$ yang dibuktikan melalui nilai posttest sehingga dapat disimpulkan bahwa model pembelajaran Numbered Heads Together berpengaruh terhadap hasil belajar kognitif siswa $\mathrm{C} 1$ sampai $\mathrm{C} 4$.

Kata kunci: hasil belajar kognitif; implementasi; numbered heads together.
\end{abstract}

\section{Abstract}

This study aims to prove the influence of the relationship between learning Numbered Heads Together on C1-C4 learning outcomes. The research method uses Quasi Experiment with Pretest Posttest Control Group design of the sampling technique used is probability sampling. The population of this research is class VIII B and class VIII D, with 27 students in each class. Retrieval of data using tests and observations of implementation, data analysis techniques with the Mann-Whitney test. The results showed that there was a relationship of learning Numbered Heads Together to learning outcomes $\mathrm{C} 1$ to $\mathrm{C} 4$ as evidenced by the Asymp.Sig value of $0,000<0.05$. Overall cognitive learning outcomes of students have reached the $\mathrm{C} 4$ realm as evidenced by the posttest value so that it can be concluded that the Numbered Heads Together learning model affects the cognitive learning outcomes of students $\mathrm{C} 1$ through $\mathrm{C} 4$.

Keywords: cognitive learning outcomes; implementation; numbered heads together.

\section{PENDAHULUAN}

Perkembangan dunia pendidikan menuntut siswa agar lebih aktif dalam proses pembelajaran di kelas sehingga guru harus menerapkan pendekatan saintifik, agar kondisi pembelajaran di kelas lebih menarik guru dapat menggunakan model pembelajaran yang mengembangkan ranah kognitif siswa. Salah satunya dengan model pembelajaran Numbered 
Heads Together, perkembangan ranah kognitif siswa sangat dibutuhkan agar siswa mampu memecahkan permasalahan yang ada baik di sekolah ataupun dimlingkungan sekitar. Dari beberapa hasil penelitian yang relevan ada beberapa perbedaan dengan penelitian yang akan dilakukan yaitu penelitian ini mengukur hasil belajar kognitif siswa dan materi yang digunakan yaitu sistem pernapasan. Berdasarkan hasil wawancara yang telah dilakukan saat pembelajaran guru masih menggunakan model pembelajaran konvesional sehingga perkembangan ranah kognitif siswa hanya mampu untuk mengingat, memahami dan mengaplikasi sedangkan ranah menganalisis belum bisa dikembangkan secara baik karena guru kurang mengaktifkan siswa dalam proses pembelajaran. Oleh sebab itu, penelitian ini dilakukan untuk menerapkan model pembelajaran Numbered Heads Together dengan hasil belajar kognitif siswa dan melihat pengaruh model pembelajaran Numbered Heads Together terhadap hasil belajar kognitif siswa $\mathrm{C} 1$ sampai $\mathrm{C} 4$.

\section{METODE}

Penelitian ini adalah Quasi Eksperimen yang menggunakan dua kelas yaitu kelas eksperimen dan kelas kontrol yang masing-masing kelas terdiri atas 27 siswa, kelas eksperimen diberikan perlakuan dengan menggunakan model pembelajaran Numbered Heads Together sedangkan kelas kontrol hanya menggunakan model pembelajaran konvensional. Teknik pengambilan sampel menggunakan simple random sampling sedangkan teknik pengumpulan data menggunakan tes dan observasi keterlaksanaan pembelajaran, sebelum melakukan pengambilan data instrumen divalidasi oleh dua orang ahli sehingga data yang diperoleh lebih valid dan akurat. Analisis data yang digunakan yaitu uji Mann-Whitney yang dilakukan dengan SPSS for windows version 20.

\section{HASIL DAN PEMBAHASAN}

Hasil penelitian yang diperoleh meliputi hasil belajar kognitif siswa, uji N-Gain dan uji Mann-Whitney. Hasil belajar kognitif siswa disajikan pada Tabel 1.

Tabel 1. Hasil Belajar Ranah Kognitif Kelas Eksperimen dan Kelas Kontrol

\begin{tabular}{cccc}
\hline Hasil Belajar & Terendah & Tertinggi & Rata-rata \\
\hline Pretest eksperimen & 60 & 80 & 71,63 \\
Posttest eksperimen & 80 & 95 & 87,85 \\
Pretest kontrol & 56 & 80 & 68,78 \\
Posttest kontrol & 70 & 80 & 80,81 \\
\hline
\end{tabular}


Tabel 1 menunjukkan bahwa kelas eksperimen nilai pretest tertinggi yaitu 80 dan nilai terendahnya 60 serta nilai posttest tertinggi 95 dan nilai terendah 80 kelas kontrol nilai pretest tertinggi yaitu 80 dan nilai terendah 56 dan nilai posttest tertinggi yaitu 89 dan nilai terendah 70. Hasil uji N-Gain akan disajikan pada Tabel 2.

Tabel 2. Rekapitulasi Perhitungan Uji N-Gain

\begin{tabular}{ccc}
\hline N-Gain & Eksperimen (\%) & Kelas kontrol (\%) \\
\hline Terendah & $20,00 \%$ & $14,29 \%$ \\
Tertinggi & $83,33 \%$ & $68,57 \%$ \\
Rata-rata & $56,7448 \%$ & $37,3586 \%$ \\
Kriteria & Cukup efektif & Kurang efektif \\
\hline
\end{tabular}

Tabel 2 menunjukkan bahwa nilai rata-rata N-Gain Score untuk kelas eksperimen dengan menggunakan model pembelajaran Numbered Heads Together sebesar 56,7448\% termasuk dalam kategori cukup efektif dengan nilai minimal 20,00 dan nilai maksimal 83,33 dan nilai rata-rata N-Gain Score untuk kelas kontrol dengan menggunakan model pembelajaran konvensional sebesar 37,3586\% termasuk dalam kategori kurang efektif dengan nilai minimal sebesar 14,29 dan nilai maksimal 68,57. Hasil uji Mann-Whitney disajikan pada Tabel 3.

Tabel 3. Hasil Perhitungan Uji Mann-Whitney

\begin{tabular}{cc}
\hline & Hasil belajar Biologi \\
\hline Mann-Whitney & 119,000 \\
Wilcoxon W & 497,000 \\
Z & $-4,327$ \\
Asymp. Sig. (2-tailed) &, 000 \\
\hline
\end{tabular}

Tabel 3 menunjukkan bahwa nilai Asymp.Sig 0,000 $<0,05$ dasar pengambilan keputusan yang dijadikan acuan dalam uji Mann-Whitney yaitu jika nilai Asymp.Sig <0,05 maka hipotesis tidak ada hubungan pembelajaran Numbered Heads Together terhadap hasil belajar C1 sampai C4 ditolak dan jika nilai Asymp.Sig >0,05 maka hipotesis ada hubungan pembelajaran Numbered Heads Together terhadap hasil belajar C1 sampai C4 diterima dengan demikian hipotesis alternatif bahwa ada hubungan pembelajaran Numbered Heads Together terhadap hasil belajar C1 sampai C4. Hasil observasi keterlaksanaan pembelajaran dengan model pembelajaran Numbered Heads Together pada materi sistem pernapasan dapat dilihat pada Tabel 4. 
Tabel 4. Rekapitulasi Tingkat Keterlaksanaan Pembelajaran Model Pembelajaran Numbered

\begin{tabular}{|c|c|c|c|}
\hline \multicolumn{4}{|c|}{ Heads Together } \\
\hline No. & Aspek yang diamati & Nilai (\%) & Kriteria \\
\hline 1 & Penyampaian tujuan pembelajaran & $28,57 \%$ & Kurang \\
\hline 2 & Pembagian kelompok yang heterogen & $57,14 \%$ & Sedang \\
\hline 3 & Penyajian permasalahan sistem pernapasan & $57,14 \%$ & Sedang \\
\hline 4 & Memberi kesempatan siswa bertanya & $42,87 \%$ & Sedang \\
\hline 5 & Setiap kelompok melakukan diskusi & $57,14 \%$ & Sedang \\
\hline 6 & $\begin{array}{l}\text { Setiap siswa memiliki catatan hasil diskusi } \\
\text { kelompok }\end{array}$ & $57,14 \%$ & Sedang \\
\hline 7 & $\begin{array}{l}\text { Siswa yang ditunjuk untuk mewakili kelompok dapat } \\
\text { menyampaikan hasil diskusi dengan baik }\end{array}$ & $57,14 \%$ & Sedang \\
\hline 8 & $\begin{array}{l}\text { Melakukan klarifikasi dan menyimpulkan hasil } \\
\text { pembelajaran }\end{array}$ & $57,14 \%$ & Sedang \\
\hline & Rata-Rata & $92,8 \%$ & Sangat Baik \\
\hline
\end{tabular}

Tabel 4 menunjukkan bahwa pembelajaran menggunakan model Numbered Heads Together pada penelitian ini terlaksana dengan sangat baik hal ini dapat dilihat dari nilai ratarata keterlaksanaan pembelajaran yaitu sebesar 92,8\% dengan kategori sangat baik.

Dua kelas yang digunakan penelitian ini yaitu kelas kontrol dan kelas eksperimen, kelas kontrol proses pembelajaran dilakukan dengan menggunakan model pembelajaran konvensional sedangkan kelas eksperimen menggunakn model pembelajaran Numbered Heads Together. Pembelajaran konvensional penyajian pembelajaran yang dilakukan oleh guru dengan penjelasan secara langsung kepada siswa atau ceramah sedangkan model pembelajaran Numbered Heads Together pembelajaran yang mengembangkan teknik belajar mengajar kepala bernomor yang dapat memberikan kesempatan kepada siswa untuk saling membagikan ide-ide, mempertimbangkan jawaban yang paling tepat dan mendorong siswa untuk meningkatkan semangat kerjasama (Lusia, 2018). Hal ini didukung oleh penelitian (Diny, 2013) yang menyatakan bahwa model pembelajaran kooperatif lebih efektif daripada pembelajaran konvensional.

Salah satu model pembelajaran yang memfasilitasi proses pembelajaran student centered adalah model pembelajaran kooperatif, ciri khas pembelajaran kooperatif adalah siswa ditempatkan pada kelompok-kelompok kerja (Nurhayati, 2011). Model pembelajaran kooperatif dikembangkan untuk mencapai hasil belaajr berupada prestasi akademik, toleransi, menerima keragaman dan pengembangan keterampilan sosial. Untuk mencapai hasil belajar itu model pembelajaran kooperatif menuntut kerja sama dan interdepensi siswa dalam struktur tugas, struktur tujuan dan struktur rewardnya (Widodo, 2008).

Nilai posttest hasil belajar kognitif siswa yang ditunjukkan pada tabel 1 memperlihatkan bahwa nilai tersebut lebih tinggi dibandingkan nilai posttest. Hal ini berarti bahwa kedua 
kelas eksperimen dan kontrol telah memiliki kemampuan belajar $\mathrm{C} 1-\mathrm{C} 4$ dengan baik, nilai tinggi pada hasil belajar kognitif pada posttest tercapai karena model pembelajaran Numbered Heads Together yang mendorong siswa untuk saling membantu, agar semua siswa dalam satu kelompok benar-benar memahami hasil diskusi yang dilakukan sehingga pada akhir diskusi ketika salah satu siswa ditunjuk untuk mewakili kelompok saat presentasi, siswa dapat melakukan tanggung jawabnya dengan hasil yang baik. Hal ini sesuai dengan pernyataan (Yanti et al, 2016) bahwa pembelajaran dengan model Numbered Heads Together dapat meningkatkan tanggung jawab siswa.

Kegiatan pembelajaran dengan menggunakan model Numbered Heads Together seperti ini membuat pemahaman siswa meningkat sehingga hasil belajar kognitif menjadi lebih optimal. Hasil perhitungan N-Gain menunjukkan bahwa nilai rata-rata kelas eksperimen lebih tinggi dibandingkan kelas kontrol dan masuk kedalam kategori cukup efektif dibandingkan kelas kontrol. Hal ini berarti bahwa model pembelajaran Numbered Heads Together dapat meningkatkan hasil belajar siswa, perbedaan nilai rata-rata kelas eksperimen dan kelas kontrol tidak terlalu signifikan hal ini dapat terjadi karena siswa pada kelas kontrol belum terbiasa dengan model pembelajaran Numbered Heads Together sehingga siswa dikelas kontrol masih belajar memahami model pembelajaran Numbered Heads Together. Menurut (Uno, 2017) belajar merupakan proses yang dilakukan seseorang untuk memperoleh suatu perubahan tingkah laku yang baru secara keseluruhan, sebagai hasil pengalaman sendiri dalam interaksi dngan lingkungan. Siswa kelas eksperimen dan kontrol berintraksi dengan model pembelajaran Numbered Head Together sehingga mengalami proses perubahan tingkah laku berupa hasil belajar kognitif.

Hasil belajar kognitif pada posttest kelas eksperimen dan kelas kontrol cukup tinggi dan mampu memperkuat hasil perhitungan $\mathrm{N}$-Gain dan membuktikan bahwa penerapan model pembelajaran Numbered Heads Together dapat mengoptimalkan hasil belajar siswa. Hal ini sesuai dengan pernyataan (Allo \& Silalahi, 2016) bahwa dengan belajar menggunakan model Numbered Heads Together hasil belajar kognitif siswa menjadi lebih baik karena model pembelajaran Numbered Heads Together merupakan model pembelajaran kooperatif yang memastikan akuntabilitas individu dalam diskusi kelompok. Pembelajaran ini memberi kesempatan kepada siswa untuk saling berbagi gagasan dan mempertimbangkan jawaban yang paling tepat, seperti hasil penelitian (Mukaromah et al, 2012) pada pembelajaran student centered learning pengetahuan yang diperoleh siswa bukan merupakan sutau pemberian melainkan hasil dari mencari, mengamati, dan mendiskusikan yang terangkum dalam serangkaian fase pembelajaran. Adapun fase atau sintaks pembelajaran Numbered Heads 
Together meliputi penomoran, penyajian masalah, diskusi, pemanggilan nomor kepala dan presentasi.

Fase penomoran mengkondisikan siswa untuk berkonsentrasi pada pembelajaran, nomor kepala yang diberikan untuk meningkatkan kesadaran siswa terhadap tanggung jawab selama proses pembelajaran karena guru dapat dengan jelas mengawasi dan memudahkan guru untuk mengeksplor aktivitas siswa dalam mencari, mengolah dan melaporkan informasi dari berbagi sumber yang diperoleh selama pembelajaran. Pada fase ini siswa diminta untuk mengumpulkan berbagi sumber belajar terkait materi sistem pernapasan agar ketika melakukan diskusi siswa dapat dengan mudah menemukan jawaban yang dicari. Fase penyajian masalah setelah siswa berkumpul dengan kelompoknya masing-masing, guru memberi permasalahan terkait sistem pernapasan, kegiatan ini berguna untuk melatih tanggung jawab secara individu maupun kelompok dalam menyelesaikan permasalahan yang ada (Dewi et al, 2012).

Kegiatan diskusi dalam kelompok guru bertugas memberikan bimbingan dan arahan bagi kelompok yang mengalami kesulitan dalam memahami permasalahan yang disajikan, dalam setiap kelompok masing-masing siswa harus dapat mengetahui dan menjelaskan jawaban yang diperkuat dengan sumber belajar sehingga informasi yang diberikan lebih akurat ketika guru memanggil perwakilan kelompok siswa dapat menjawab dengan benar. Hal ini melatih kerjasama antara siswa dan kelompoknya untuk dapat menjelaskan kepada teman yang kurang memahami jawaban yang sudah diperoleh sehingga semua anggota mengetahui jawaban dari masing-masing pertanyaan (Wijayati, 2013).

Secara acak guru memilih dan memanggil nomor dikepala siswa untuk menjawab permasalahan yang sudah diselesaikan, hal ini melatih kebenarian siswa untuk dapat menjelaskan hasil diskusi didepan kelas. Sebelum mengakhiri pembelajaran guru memberi penegasan atas jawaban yang sudah disampaikan oleh beberapa kelompok serta diakhir pembelajaran guru bersama siswa menyimpulkan materi tentang sistem pernapasan (Siregar, 2012).

Keterlaksanaan pembelajaran dengan menggunakan model Numbered Heads Together pada Tabel 4 menunjukkan kategori sangat baik, hal ini dapat terjadi karena model pembelajaran Numbered Heads Together dapat membuat suasana kelas lebih menarik sehingga siswa dapat mengikuti pembelajaran dengan sangat baik. Menurut (Walberg \& Greenberg 1997) bahwa suasana kelas adalah penentu psikologis utama yang mempengaruhi belajar akademis. Hal ini didukung (Wang, 2015) bahwa pembelajaran kooperatif mampu 
mendorong keaktifan siswa dan membuat suasana belajar menyenangkan dan tidak membosankan dikarenakan siswa bekerja secara kelompok untuk menemukan sendiri pengetahuan yang diperlukan dan dapat bertukar pengetahuan dengan teman lainnya.

Keunggulan model pembelajaran Numbered Heads Together yang diterapkan yaitu menjadikan siswa memiliki pemahaman lebih terhadap materi yang dipelajari sehingga berdampak pada hasil belajar, pembelajaran dengan model Numbered Heads Together memberikan kesempatan lebih luas kepada siswa untuk terlibat aktif dalam proses pembelajaran. Siswa belajar dari teman melalui diskusi kelompok sehingga dapat saling mengoreksi apabila ada salah satu anggota kelompok yang tidak tau atau kurang memahami materi, model pembelajaran Numbered Heads Together menuntut masing-masing siswa untuk mengerti apa yang menjadi pemikiran dalam kelompoknya, hal tersebut sesuai dengan pendapat (Slavin, 2010) yang menyatakan bahwa Numbered Heads Together memungkinkan setiap siswa aktif dalam diskusi dengan teman sekelompoknya sehingga terjadi komunikasi yang baik antar siswa dan membuat siswa aktif bekerjasama dalam diskusi kelompok.

Kelebihan model pembelajaran Numbered Heads Together adalah setiap siswa menjadi siap semua, dapat melakukan diskusi dengan sungguh-sungguh dan siswa yang pandai dapat mengajari temannya yang kurang pandai, namun terdapat kelemahan dalam model pembelajaran Numbered Heads Together yaitu kemungkinan nomor yang dipanggil, dipanggil lagi oleh guru dan tidak semua anggota kelompok dipanggil oleh guru (Nihayah, 2009).

\section{SIMPULAN}

Pembelajaran model Numbered Heads Together dapat meningkatkan hasil belajar siswa kelas VIII materi sistem pernapasan di SMP Muhammadiyah 5 Yogyakarta. Hasil belajar ranah kognitif ditunjukkan dengan peningkatan pemahaman siswa terhadap materi sistem pernapasan dengan rata-rata nilai $\mathrm{N}$-Gain sebesar $56,7448 \%$ yang cukup efektif untuk meningkatkan hasil belajar kognitif siswa C1-C4.

\section{REFERENSI}

Allo, L. S. \& D. K. Silalahi, 2016. Peningkatan Hasil Belajar Kognitif Siswa dengan Menggunakan Metode Numbered Heads Together (NHT) dalam Pelajaran Biologi Kelas VII di SMPK Medan. EduMatSains 1 (1): 83-94. 
Dewi, R,P.,R, S. Iswari, R. Susanti \& Supriyanto. 2012. Penerapan Model Group Investigation Terhadap Hasil Belajar Materi Bahan Kimia di SMP. Unnes Journal of Biology Education 1 (3): 279-286.

Diny Dwi Febriany. 2013. Pengaruh Pembelajaran Kooperatif Tipe Numbered Heads Together (NHT) untuk Meningkatkan Hasil Belajar Akuntansi. Jupe UNS, Vol 1, No 2 Hal 1 s/d 11.

Lusia Retno Yuliani, dkk. Penerapan Model Pembelajaran Numbered Heads Together (NHT) Terhadap Hasil Belaajr Siswa pada Materi Sistem Ekskresi. Journal of Biology Education 7(2) (2018): 209-215

Mukaromah, E., S. H.Bintari, \& I. Mubarok. 2012. Hasil Belajar Siswa pada Materi Protista Akibat Penerapan Model Learning Cycle. Unnes Journal of Biology Education 1(2): 182-189.

Nihayah, Ainun. 2009. Upaya Meningkatkan Hasil Belajar Biologi Melalui Model Pembelajaran Kooperatif Tipe Numbered Heads Together (NHT). Semarang. Institut Agama Islam N egeri Walisongo Semarang.

Nurhayati. 2011. Strategi Belajar Mengajar. Makassar, Badan Penerbit Univeristas Negeri Makassar.

Siregar, F. A. 2012. Pengaruh Model Kooperatif Tipe NHT Terhadap Hasil Belajar Siswa Kelas VIII SMP Negeri 18 Medan. Jurnal Pendidikan Fisika, 1(1) 33-38.

Slavin, R.E.2011. Cooperative Learning Teori, Riset dan Praktik. Bandung: Nusa Media.

Uno. 2011. Model Pembelajaran. Jakarta: Bumi Aksara.

Widodo. 2008. Penerapan Pendekatan Kooperatif Tipe Numbered Heads Together untuk Meningkatkan Kompetensi Pendidikan Semarang. Universitas Negeri Semarang.

Walberg, H.B. \&R.C. Greenberg. 1997. Using the Learning Environment Inventory. Educational Leadership 54 (8): 45-47.

Wang, X. 2015. A Study on Cooperative Learning of Collage English Teaching. Journal of English Language Teaching 2(3): 9-13.

Wijawati, Nanik. 2013. Penggunaan Model Pembelajaran Numbered Heads Together untuk Meningkatkan Hasil Belajar Kimia Universitas Negeri Semarang. Jurnal Inovasi Pendidikan Kimia, Vol.2, No 2, hlm 281-286.

Yanti, K.D., D., P. Parmiti \& I. I.W. Suwatra. 2016. Pengaruh Model Pembelajaran Kooperatif Tipe Numbered Heads Together (NHT) terhadap Hasil Belajar IPA. EJournal PGSD Universitas Pendidikan Ganesha 4(1):1-10. 